\title{
Preface
}

\begin{abstract}
1 PAINTER, sculptor, photographer, printmaker, sometime performance choreographer, and maker of hybrid forms thereof, Robert Rauschenberg is widely considered to be one of the most influential American artists of the twentieth century. In June 2013, the Columbia Center for Oral History Research was awarded a grant from the Robert Rauschenberg Foundation to conduct a project on the life and influence of the artist, and we realized that creative challenges lay before us. The first set of challenges were methodological; we learned a great deal about how to link our practices in the oral history world with similarly rigorous practices in the art world, resulting in creative exchanges and new standards.
\end{abstract}

\section{METHODOLOGICAL CHALLENGES}

During the project's pilot phase, the Rauschenberg and Columbia teams came to understand a difference in their respective fields. Oral historians and art historians think about subjectivity in different ways. In oral history, we are aware that we are studying memory itself, and we allow for its rearrangements, which reveal different meanings. Art historians understandably place great value on exact record keeping, preserving each image and its source with care to allow direct access to others. This difference led to the creation of a new step in processing the transcript. The normal work flow at the Columbia Center for Oral History Research is as follows: conduct an interview, have it transcribed, audit-edit the transcript (making sure the transcript is an accurate record of 
the audio file), and return it to the narrator for his or her edits. On the Rauschenberg project, we added a new step-fact-checking the transcripts. In addition to confirming proper names, we checked for accuracy and full expression of titles of Rauschenberg's work, including the date of all creative works, and checked for accuracy of descriptions of pieces, exhibitions, and locations when a narrator mentioned Rauschenberg was present. The foundation staff provided further research into Rauschenberg's artistic processes as well as details pertaining to all other artists' work.

Fourteen video sessions were conducted for the project, including a number of what we called technical oral histories, a hybrid interview form that was conducted with Rauschenberg's former studio assistants and fabricators. These interviews were captured on film and were shot in the presence of artworks to best facilitate in-depth discussions about the materials and methods used in their creation. These interviews were held at the Rauschenberg warehouse in Westchester, New York, which houses the foundation's art collection and some archival material. Each narrator identified the series to which he would like to speak, Rauschenberg Foundation collections manager Gina Guy found the best examples of that series still in the collection, and Rauschenberg's then senior registrar, Thomas Buehler, installed them in the warehouse space so that narrators could literally speak to, and about, the work. Columbia interviewers collaborated with conservator Christine Frohnert to collect the story and the process behind each work of art displayed.

Overall, the interviewing team completed ninety-eight oral history sessions with fifty-nine narrators, totaling 179 recorded hours. These reminiscences are archived at the Columbia University Center for Oral History Archives at the Rare Book \& Manuscript Library in Butler Library and at the Rauschenberg Foundation.

A very dynamic challenge in the Robert Rauschenberg project was that we needed to depend on those who were close to the artist-his friends and family, curators, critics, and others-to paint a picture of his world after his death. Due to the careful work of the Rauschenberg Foundation, who connected us to his network, and of the extraordinary work of the interviewers who stimulated narrators to reconstruct memories of Rauschenberg's world, the art world, and their own memories, the project came to life. This says something very positive about the tangible legacy Robert Rauschenberg left 
and the creative ability of oral history to resurrect the past for the sake of transmitting memory.

Our objective was to establish an oral biography of the artist by recording firsthand accounts of his life, work, and legacy as told by his family, friends, former lovers, professional associates, studio assistants, and collaborators. We also strove to capture the spirit of the larger art world that Rauschenberg inhabited throughout his life. Drawing from a consideration of Rauschenberg's life and work situated within the larger scope of art and social history, we identified four periods of inquiry: the 1950 s and 1960s, the 1970s, the 1980s, and the 1990 s until Rauschenberg's death in 2008 . We attempted to capture three vital strands in each period: Rauschenberg's life and legacy as told through the interviews we conducted; the contributions of the individuals we interviewed to the art world of their times; and how, through innovation and experimentation, Rauschenberg and his collaborators influenced each other to create something new.

The materials held at the Robert Rauschenberg Foundation were invaluable to our preparation. The large collection of letters to Rauschenberg from his colleagues in the art world, writings by the artist, the collection of documentary photographs relating to Rauschenberg's art and life, sketches, exhibition photos, newspaper clippings of interviews with Rauschenberg, reviews of his exhibitions, an extensive collection of exhibition catalogs organized by year, posters, and other assorted archival documents and books were all made available to our interviewers.

The second set of challenges we faced was theoretical. Although oral history has recorded the art world at Columbia and beyond, it is only recently that we have considered the still photograph, the moving image, and dance and performance as primary sources. To help you understand how we approached the visual and embodied world of Robert Rauschenberg, we next provide a brief review of the nature of oral history's contribution to an understanding of visual history and memory.

\section{ORAL HISTORY: THE VISUAL ARTS AND MEMORY}

In the introduction to The Art of Memory, Frances Yates writes that "in the ages before printing a trained memory was vitally important and the 
manipulations of images in memory must always to some extent involve the psyche as a whole." Yates's phrase, "psyche as a whole," is analogous to what oral historians would call "subjectivity," the intimate yet enormous world we carry inside of us that defines who we were, who we are, and who we aspire to become in relation to many external worlds. Oral history is the intersubjective and dialogical activity of exploring the past in relation to the present and the future; it is itself an art form that also involves capturing the psyche as a whole as well as the particular social and historical contexts that define subjectivity. In that sense, the work of the oral historian and the work of the artist and of art historians are deeply interconnected, even though it is only recently that oral historians have come to embrace memory in its visual, embodied, and tangible forms. We are fortunate that work on the Robert Rauschenberg Oral History Project coincided with a time that began to embrace the visual world within oral history, providing a context through which we could explore the synergies between our disciplines and artistic forms. To better understand the exciting symmetries between oral history and the arts that exist now, it is important to understand that until recently the modern oral history profession favored suppressing the visual image, and the body as well, in highlighting the importance of the written word. In many ways, understanding the arts has contributed to the growth of a new and visual form of oral history.

Oral history, classically defined as being as old as the act of speech and as constant as the activity of passing down stories to preserve the intimate and tangible memory of cultures, flourished long before there was a name to describe the activity. ${ }^{2}$ As Frances Yates so beautifully records in her history of how visual memory preserved history through art and architecture in The Art of Memory, the act of transmitting memory was connected to the art of telling, mnemonically and historically. In the transmission of memory, the orality of the word and the subjectivity of the image belong to one another organically in the transmission of memory through art and architecture. Mnemosyne, the mother of all muses, enables the fullness of memory to flow through time, integrating the image with the spoken word in the performance of stories. In Yates's world, the word and the image belong together to such a degree that memory cannot perform its function without one or the other. The visual imaginary is part of subjectivity and the art of transmitting memory in its fullest, most embodied sense. 
In a sensory inclusive definition of oral history, the visual artist and the oral memoirist play a similar role. Through the integration of the word and the image, a "picture" of the still living past is created so that the renewal of memory can occur. It is through this reinvigoration of memory that the images and words of one generation are passed to another even when, important to oral history, the language of memory has been lost, erased, or not recorded at all. Jan Assmann has written about how, in this sense, oral memory is deeply connected to archeology, a process of restoring the past through examining the traces of visual memory in palimpsests for what remains in an effort to restore memory. ${ }^{3}$ Andreas Huyssen, in Present Pasts: Urban Palimpsests and the Politics of Memory, argues that a palimpsest is an evocative symbol of the violence of erasure in the twentieth century, an erasure that in the end stimulated cultural memory studies, memorials, and films obsessed with what has been lost. ${ }^{4}$

Oral history, in its modern form dating to the 1930s and 1940s, had little interest in the visual and aural dimensions of the story and almost no interest in subjectivity or memory. In the United States, oral history was defined as a source of historical evidence that, like letters, diaries, and other documents, were most valuable in their written form. Allan Nevins, founder of the Center for Oral History Research at Columbia in 1948, instructed his staff to reuse the reel-to-reel tapes to save money. In fact, some oral historians in the United States have argued that oral history does not meet the standard of evidence as oral history until it is deposited into an archive and made accessible. Aside from a few pictures of notable narrators and staff, no visual evidence of oral history activity existed until the late 1990s, when the Center for Oral History was given a grant from the Carnegie Corporation to shoot video and use photographs to create a more public and visible legacy of its work and to create a field of visual oral history. Our mutual goal was to create a field of visual oral history that retained the scholarly values of oral history but would expand its public use by making it accessible through visual media on the internet.

One early manifestation of the positive results of telling a scholarly and public story through visual media was our Carnegie Corporation Oral History Project, Phase II, oral history. Specifically, we produced a website and video, "Voices from South Africa," that traced Carnegie supported research on white poverty in the 1930s, which was used to create a blueprint for apartheid, and later black poverty in the 1970s and 1980s, which was used for the cause of 
liberation. These two oppositional and entangled histories came to life through images of black and white poverty, visual digital transcripts, and the videotaped narratives that expressed the strong emotional content of South Africa's contested past as well as its conflicted history.

\section{A REVALUING OF ORAL SOURCES}

Luisa Passerini, an Italian intellectual historian with a strong interest in the impact of fascism on the working classes, was one of the first historians to use oral history for the purposes of analyzing oral sources for evidence of the legacy of fascism in ordinary lives. In her landmark article, "Work Ideology and Consensus Under Italian Fascism," she described the value of oral sources in interpreting the subjective violence of fascism. Passerini connected the analytical use of oral sources as a primary methodology for recording the complex impact of political history and violence in ways that historians using only written sources could not. In fact, she argued that Italian historiography at the time had no methodology for interpreting the silences and distortions of memory that she found regularly in her interviews. Passerini's thesis had a tremendous impact on the growing field of culturally sensitive oral historians and others, separating empirical oral historians from those who acknowledged the ambiguities and contradictions in oral history as a source of valuable knowledge. ${ }^{6}$

Alessandro Portelli, an Italian oral historian writing and researching on the complex legacy of fascism in the same time frame, used his training as a literary scholar to expand on the ways in which oral sources are bound in time in folk traditions and are expressions of history, memory, and ideology in the form of their telling. ${ }^{\text {? }}$

As the field of oral history grew through the remarkable efforts of Luisa Passerini, Alessandro Portelli, and others, who turned to the voice itself and the languages of memory within the voice, scholars and practitioners around the world began to see the value of oral history in interpreting political and culture violence, displacement, and loss. Even without a focus on the visual imaginary in the 1970s and 1980s, oral history stretched to include the "wholeness" of memory and experience, retold in order to be interpreted not only for the past 
but for the living present. Portelli made specific contributions to expanding the field of oral history by demonstrating how oral memory can reverse popular collective memory in his magnum opus, The Order Has Been Carried Out: History, Memory and Meaning of a Nazi Massacre in Rome. The award-winning book excavates a memory of a Nazi massacre of over three hundred people, blamed on a small group of partisans who attacked a group of Nazis near the end of World War II. The Nazis reported after the massacre that the partisan attackers were ordered to turn themselves in or ten times the number of partisans would be shot. In fact, Portelli discovered, through an extensive number of interviews with surviving family members and others, that the order was never posted. The architecture of the book itself, framed by first person testimony of surviving family members and others, serves to literally deconstruct an official memory and replace it with an authentic one constructed from five decades of living memory. ${ }^{8}$

Most important for the teaching of oral history theories that underlie the intersubjective structure of the oral history interview, Passerini's book, Memory and Utopia: The Primacy of Intersubjectivity, clearly defined the multiple ways in which subjectivity defines the content and shape of oral history. ${ }^{9}$ This is true, she argued in the International Oral History Association's meeting in Rome in 2004, even when a breakdown of communication occurs, mirroring social differences that cannot be bridged but must be understood. She was already beginning to apply that rigor to her own work, understanding the cultural limits of Europe through the stories of those who crossed its borders to seek refuge.

Passerini, Portelli, and others, including Raphael Samuels in Britain (Theaters of Memory), succeeded in introducing the idea of cultural memory and subjectivity to the oral history world through their examination of "orality" and, in Samuel's case, visual images as primary sources, ideas that spread throughout the oral history world in the 1980 os and 1990s. With their contributions, the field of oral history-as it expanded to include a worldwide community of scholars-began to shape its own expectations as a multidisciplinary field of study and practice that went far beyond the goal of populating the archive with transcripts. The small but intensive gatherings of global oral historians expanded into international meetings through which broader conversations were held about the relationship between history and memory, including how 
oral history might address and redress historical violence. It became clear that oral history could be a platform for deep exchanges on politics, culture, and memory in multidisciplinary and cross-cultural contexts. As the field grew through these international meetings, leaders began to ask probing questions about the future of oral history.

\section{A VISUAL TURNING POINT}

It was during the 1993 meeting of an international group of oral historians, gathered in Siena, Italy, that Passerini issued an urgent call for the use of visual sources that was as powerful as her passionate call for the use of oral sources had been in 1979. During an already enlivened debate about whether the nascent international oral history group would expand outside of Europe's borders, she stood up in a general meeting and declared, "Unless and until oral history moves into the visual realm of memory, it will inevitably die." ${ }^{10}$ Those of us who witnessed this call also heard the collective silence of the group that was gathered, astonished at the strength of her Cassandra-like prophecy that, instinctively, many of us knew to be true if the field was truly turning toward representing the voices of those who were rarely represented in the Western canon and its written histories.

In retrospect, it is easy to see how the themes of the 1993 Sienna conference stimulated Passerini's call for visual oral history as the ideal form through which to capture turbulent historical times. The key themes of the Sienna conference-migration, generation, gender, and the processes of identity and cultural construction-carry within them the imagination of the body itself as a locus of identity and mobility. Passerini has devoted the last five years of her work to these themes, exploring these ideas in depth through the lens of visual representations of living memory and the experience of recent migrants traveling to Europe.

This shift to the incorporation of visual materials in oral history has been carried forward by others. Ann Cvetkovich, a noted literary critic and author of An Archive of Feelings: Trauma, Sexuality and Lesbian Public Cultures, analyzed ACT-UP New York's collection of images and videos in relation to her own oral interviews, making the argument that public activism can be a form 
of resistance against historical trauma. In so doing, she made a parallel claim to that of Passerini-to ignore the life of the body is to ignore history itself. Beyond that, and in a framework similar to that of Passerini's, Cvetkovich put forth the idea that embodiment is central to oral history work and analysis, and that without it, it is impossible to understand the transformative potential of cultural and political movements. ${ }^{11}$ Kathy Davis examined how feminist theory and the body intersect in her landmark book, The Making of Our Bodies, Ourselves: How Feminism Travels Across Borders. In the same general time period, dance and oral history scholar Jeffrey Friedman, who did extensive interviews with artists with AIDS in San Francisco, made the argument that oral history was directly linked to the worlds of performance and dance with the body as the focus of the process of meaning-making. Della Pollack, in Remembering: Oral History Performance, instantiated performance studies as a part of oral history. Although Alex Freund and Alistair Thomson's 2011 edited collection, Oral History and Photography, is limited to an examination of the value of the still image, it makes a valuable point that the oral and the visual are deeply linked, especially in memory work.

\section{RESONANCES}

The synchronicities between the fields of art history, the study of memory, and the growth of oral history have been striking to us in the time frame during which the Robert Rauschenberg Project was completed. As we were learning about the importance of bringing the world into the interview room, we were listening to narrators in the Rauschenberg project discussing ways Rauschenberg insisted on the same. As we were realizing that there is no way to capture the wholeness of the psyche without the literal memory of embodiment, we were analyzing the stories of how Rauschenberg came to life when he began to collaborate with dancers. As we have been wondering how to think about objects of memory in oral history interviews, we were learning about how Rauschenberg, led the art world in recognizing their literal and symbolic value inside the museum. As we were loosening the grip of the archive on our thinking processes about how oral history is defined and what interviews we conduct, we were inspired by Rauschenberg's insistence that museums open 
xviii • Preface

their doors to incorporate the art and artifacts of real life-to let the world in. Robert Rauschenberg's life and work, including his philanthropy, aspired to create new forms and utopian possibilities. This oral biography of Robert Rauschenberg, told in multiverse, is our attempt to strengthen our collective understanding of his impact, not only on the art world but on all the audiences he reached. 